\title{
Development and Optimization of a Novel Prolonged Release Formulation to Resist Alcohol-Induced Dose Dumping
}

\author{
Chaitanya Yogananda Gujjar, ${ }^{1,2}$ Balaramesha Chary Rallabandi, ${ }^{1}$ \\ Ramesh Gannu, ${ }^{1}$ and Vallabh Subashrao Deulkar ${ }^{1}$
}

Received 20 January 2015; accepted 18 June 2015; published online 11 July 2015

\begin{abstract}
Alcohol-induced dose dumping is a serious concern for the orally administered prolonged release dosage forms. The study was designed to optimize the independent variables, propylene glycol alginate (PGA), Eudragit RS PO (ERS) and coating in mucoadhesive quetiapine prolonged release tablets $200 \mathrm{mg}$ required for preventing the alcohol-induced dose dumping. Optimal design based on response surface methodology was employed for the optimization of the composition. The formulations are evaluated for in vitro drug release in hydrochloric acid alone and with $40 \% v / v$ ethanol. The responses, dissolution at $120 \mathrm{~min}$ without alcohol (R1) and dissolution at $120 \mathrm{~min}$ with alcohol (R2), were statistically evaluated and regression equations are generated. PGA as a hydrophilic polymeric matrix was dumping the dose when dissolutions are carried in $0.1 \mathrm{~N}$ hydrochloric acid containing $40 \% \mathrm{v} / \mathrm{v}$ ethanol. ERS addition was giving structural support to the swelling and gelling property of PGA, and thus, was reducing the PGA erosion in dissolution media containing ethanol. Among the formulations, four formulations with diverse composition were meeting the target dissolution (30-40\%) in both the conditions. The statistical validity of the mathematical equations was established, and the optimum concentration of the factors was established. Validation of the study with six confirmatory runs indicated high degree of prognostic ability of response surface methodology. Further coating with ReadiLycoat was providing an additional resistance to the alcohol-induced dose dumping. Optimized compositions showed resistance to dose dumping in the presence of alcohol.
\end{abstract}

KEY WORDS: alcohol dose dumping; Eudragit RS PO; optimal design; propylene glycol alginate; quetiapine prolonged release.

\section{INTRODUCTION}

Quetiapine Fumarate $(\mathrm{QF})$ is a psychotropic agent indicated for the treatment of schizophrenia and manic episodes associated with bipolar disorder. QF possesses good solubility in aqueous fluids (1) and ethanol. Quetiapine is available in the US market with the brand name of Seroquel XR (2). Inadvertent, rapid release of drug in a small period of time, entire amount, or a significant fraction of the drug from a prolonged release dosage form is often referred to as "dose dumping". Anand O. et al. highlighted United States FDA's perspective on the dose dumping in general for modifiedrelease dosage forms in the presence of alcoholic beverages and FDA's efforts to reduce the regulatory burden and unnecessary human studies in generic drug development (3). Subject to the therapeutic indication and the therapeutic index of the drug, dose dumping can pose a significant risk to patients either due to the safety issues or abate efficacy or both (4).

\footnotetext{
${ }^{1}$ AET Laboratories Private Limited, Survey. No. 42, Gaddapotharam, Kazipally Industrial Area, Medak (Dist.), 502319, India.

${ }^{2}$ To whom correspondence should be addressed. (e-mail: g.chaitanya@aet.in)
}

In previous findings by authors, mucoadhesive quetiapine prolonged release tablets prepared by using propylene glycol alginate (PGA) showed that it can be effectively used as controlled release polymer (5). It was observed that the tablets showed prolonged release in $0.1 \mathrm{~N}$ hydrochloric acid, acetate buffer solution $\mathrm{pH} 4.5$, and phosphate buffer solution $\mathrm{pH}$ 6.8. These formulations were found to be disintegrating relatively quickly and dumped the dose when dissolution tests were performed in $0.1 \mathrm{~N}$ hydrochloric acid containing $40 \%$ alcohol. According to the United States food and drug administration guidance, alcohol-motivated dose dumping studies must be performed for quetiapine prolonged release tablets at alcohol concentrations of 5,20, and $40 \%$ in $0.1 \mathrm{~N}$ hydrochloric acid (6). An ideal prolonged release formulation should have similar dissolution profiles for dissolution tests performed with and without alcohol in $0.1 \mathrm{~N}$ hydrochloric acid.

Jedinger et al. (2014) reviewed the physicochemical key factors to be considered in the preparation of alcohol-resistant controlled release dosage forms. They highlighted the availability of a limited number of robust dosage forms that withstand the impact of alcohol (7). Johnson et al. (2008) studied the relative bioavailability of extended-release morphine sulfate capsules coated with drug retarding polymer (KADIAN, 
$100 \mathrm{mg}$ ) (8). Palladone ER capsules (hydromorphone hydrochloride) were withdrawn in light of alcohol-induced dose dumping risk (9). Rosiaux et al. (2013) studied theophylline release from pellets coated with the aqueous ethylcellulose dispersion Aquacoat $\AA$ ECD 30 containing 10 or $15 \%$ medium and high viscosity guar gum for alcohol-induced dose dumping. Pellets coated with blends of ethylcellulose and medium or high viscosity guar gum were virtually unaffected by the addition of $40 \%$ ethanol to the release medium (10). Water soluble polymers and water insoluble polymers should exhibit resistance to dose dumping in prolonged release or sustained release dosage forms intended for oral administration. The use of water soluble polymers like hypromellose (11), hydroxyethyl cellulose (12), carbopol (13), and sodium carboxymethyl cellulose (14) has been reported in such studies.

PGA is a propylene glycol ester of alginic acid, a straight glycuronan polymer consisting of a mixture of $\beta-(1 \rightarrow 4)$-Dmannosyluronic acid and $\alpha-(1 \rightarrow 4)$-L-gulosyluronic acid residues. PGA possesses solubility in aqueous solutions containing up to $60 \% w / w$ of ethanol (95\%). PGA is well known stabilizing, suspending, gelling, and emulsifying agent and is normally used in oral and topical dosage forms (15).

Eudragit RS PO (ERS) is a copolymer of ethyl acrylate, methylacrylate, and a low content of methacrylic acid ester with quaternary ammonium groups. ERS has been used as a controlled release agent and possesses poor mucoadhesive properties (16). The quetiapine tablets prepared during screening with ERS alone as a polymer for tablet matrix resulted in dose dumping in the presence of alcohol.

Opadry® II Yellow 85F32004 (Opadry II) is a coating material in which polyvinyl alcohol is a film forming polymer (17). In general, polyvinyl alcohol is used as coating agent, lubricant, and stabilizing agent in formulations. It is soluble in water and slightly soluble in ethanol (95\%) (18). ReadiLycoat is a ready to use coating material containing modified hydroxypropyl starch as film former. Hydroxypropyl starch is a binding and thickening agent. It has reported use in controlled-release drug delivery systems as hydrophilic matrices (19).

The objective of the investigation was to optimize novel combination of polymers PGA and ERS in mucoadhesive quetiapine prolonged release tablets $200 \mathrm{mg}$ based on statistical design. The role of combination of polymers in tablet matrix and coating in resisting the alcohol-induced dose dumping was estimated. All the formulations were evaluated for dissolution in $0.1 \mathrm{~N}$ hydrochloric acid with and without $40 \% \mathrm{v} / \mathrm{v}$ ethanol.

\section{MATERIALS AND METHODS}

\section{Materials}

Quetiapine Fumarate was received as purchased sample from Matrix Laboratories Limited, Hyderabad, India. PGA (Kelcoloid K3B426, FMC Biopolymer) ReadiLycoat (Roquette), copovidone (Plasdone S-630, ISP), and microcrystalline cellulose (Avicel® PH 101, FMC Biopolymer) were received as gift samples from Signet Chemical Corporation, Mumbai, India. Eudragit RS PO was received from Evonik,
Mumbai, India, as gift sample. Opadry II Yellow 85F32004 was received as gift sample from Colorcon, India.

\section{Methods \\ Design of Experiments}

The experiments were designed using statistical software tool Design Expert, version 9.0 (State-Ease, Minneapolis, $\mathrm{MN})$. The experimental design chosen was based on response surface methodology (RSM) (20) to optimize the levels of PGA and ERS. RSM is a collection of mathematical and statistical techniques for empirical model building. The quantities of independent variables $\left(X_{1}, X_{2}\right.$, and $\left.X_{3}\right)$ in the formulations were changed in master composition for each experimental trial as per Tables I and II. All the experiments were conducted using similar process and processing parameters. I-Optimal statistical design was used to statistically optimize the formulation factors and evaluate the main effects, interaction effects, and cubic effects (21) on the dissolution of QF at 120 min. A three-factor 2-level I-Optimal design was used to explore quadratic response surfaces and constructing second-order polynomial models. The I-Optimal design was specifically selected since it required fewer runs than a central composite design in cases of three variables. This cubic design is outlined by set of points lying at various locations of the cube. A design matrix constituting of 18 experimental runs was constructed. The dependent and independent variables (PGA, $X_{1}$; ERS, $X_{2}$; and coating, $X_{3}$ ) selected are shown in Table I along with their high and low levels and were chosen based on the results of earlier work $(5,22)$.

\section{Preparation of Tablets}

QF, microcrystalline cellulose, PGA, and ERS were sifted separately through sieve, 30 mesh. The sifted materials were loaded into the high shear mixer granulator (Kevin, HSMG 10, Ahmadabad, India) and mixed for $5 \mathrm{~min}$. Binder solution was prepared separately by dissolving copovidone in isopropyl alcohol under stirring. The binder solution was added to the high shear mixer granulator containing the physical mixture at slow speed for 2 min to form a wet granular mass. The mass was dried in fluid bed processor (FBE-5, Pam Glatt, Mumbai, India) at $60^{\circ} \mathrm{C}$ as the inlet temperature to achieve loss on drying of the granules less than $3 \% w / w$. The dried granules were sized using comil (Quadro Engineerig, U5-0421, Waterloo, Canada) and sieved through 25 mesh. The extra granular materials, colloidal silicone dioxide, and magnesium stearate were sifted through 30 mesh. The dried granules and sifted extra granular excipients were blended for $5 \mathrm{~min}$ in blender (Kalweka HD-410 AC, Ahmedabad, India). The tablets were compressed on single rotary tablet compression machine (Cadmach, CMD3-16, Ahmedabad, India).

\section{Coating of the Tablets}

The coating solution was prepared by dispersing Opadry II Yellow 85F32004 or Readilycoat in purified water and stirred for $45 \mathrm{~min}$. The tablets were coated in automated perforated coating machine (Ganscoater, GAC-275, Thane, India) at an inlet temperature of $55^{\circ} \mathrm{C}$. 
Table I. Variables and Responses of Quetiapine Prolonged Release Tablets $200 \mathrm{mg}$

\begin{tabular}{|c|c|c|c|c|c|}
\hline \multirow[t]{2}{*}{ Composition } & \multicolumn{3}{|l|}{ Variables } & \multicolumn{2}{|c|}{ Responses $($ mean $\pm \mathrm{SD})$} \\
\hline & $X_{1}$ & $X_{2}$ & $X_{3}$ & $\mathrm{R} 1$ & $\mathrm{R} 2$ \\
\hline $\mathrm{F} 1$ & 97.242 & 89.400 & ReadiLycoat & $45 \pm 3.2$ & $69 \pm 3.6$ \\
\hline $\mathrm{F} 2$ & 98.227 & 60.000 & Opadry II & $44 \pm 4.1$ & $79 \pm 3.7$ \\
\hline $\mathrm{F} 3$ & 95.920 & 132.969 & Opadry II & $39 \pm 2.7$ & $55 \pm 2.8$ \\
\hline $\mathrm{F} 4$ & 75.000 & 131.925 & ReadiLycoat & $40 \pm 3.2$ & $52 \pm 3.4$ \\
\hline F5 & 75.000 & 165.000 & Opadry II & $38 \pm 4.2$ & $57 \pm 4.6$ \\
\hline F6 & 127.500 & 136.125 & ReadiLycoat & $36 \pm 1.6$ & $39 \pm 1.9$ \\
\hline F7 & 150.000 & 136.507 & Opadry II & $32 \pm 1.9$ & $39 \pm 2.3$ \\
\hline F8 & 150.000 & 93.600 & ReadiLycoat & $34 \pm 2.3$ & $45 \pm 2.7$ \\
\hline F9 & 125.409 & 165.000 & Opadry II & $31 \pm 2.1$ & $37 \pm 3.8$ \\
\hline F10 & 75.000 & 98.325 & ReadiLycoat & $44 \pm 4.0$ & $80 \pm 3.7$ \\
\hline F11 & 75.000 & 60.000 & ReadiLycoat & $46 \pm 4.2$ & $100 \pm 5.6$ \\
\hline $\mathrm{F} 12$ & 95.625 & 165.000 & ReadiLycoat & $40 \pm 3.3$ & $42 \pm 4.9$ \\
\hline F13 & 150.000 & 165.000 & ReadiLycoat & $30 \pm 1.3$ & $30 \pm 1.2$ \\
\hline F14 & 129.317 & 90.993 & Opadry II & $37 \pm 2.8$ & $59 \pm 3.5$ \\
\hline F15 & 129.000 & 60.000 & ReadiLycoat & $38 \pm 1.9$ & $71 \pm 2.4$ \\
\hline F16 & 95.920 & 132.969 & Opadry II & $40 \pm 2.0$ & $54 \pm 2.7$ \\
\hline F17 & 75.000 & 88.875 & Opadry II & $45 \pm 5.1$ & $99 \pm 5.6$ \\
\hline F18 & 150.000 & 60.000 & Opadry II & $35 \pm 3.2$ & $75 \pm 4.5$ \\
\hline \multicolumn{6}{|c|}{ Independent and dependent variables used in design of experiments } \\
\hline Variables & Name & Type & Low & High & \\
\hline$X_{1}$ & PGA (mg) & Numeric & 75 & 150 & \\
\hline$X_{2}$ & ERS (mg) & Numeric & 60 & 165 & \\
\hline$X_{3}$ & Coating* & Categoric & Opadry II & ReadiL & \\
\hline \multicolumn{6}{|l|}{ Responses } \\
\hline $\mathrm{R} 1$ & \multicolumn{5}{|c|}{ Dissolution at 120 min without alcohol (\%) } \\
\hline $\mathrm{R} 2$ & \multicolumn{5}{|c|}{ Dissolution at 120 min with alcohol (\%) } \\
\hline
\end{tabular}

*Opadry II Yellow 85F32004 or ReadiLycoat

\section{In Vitro Drug Release Studies}

The in vitro drug release of quetiapine from $\mathrm{QF}$ prolonged release tablets $200 \mathrm{mg}(n=12)$ was performed using USP I (basket) apparatus (Electrolab, 2695 separation mod-

Table II. Master Composition of Quetiapine Prolonged Release Tablets $200 \mathrm{mg}$

\begin{tabular}{|c|c|c|}
\hline Ingredients & $\begin{array}{r}\text { Factor } \\
\text { type }\end{array}$ & $\begin{array}{l}\text { Composition } \\
\text { (mg/tablet) }\end{array}$ \\
\hline \multicolumn{3}{|l|}{ Stage-A (Dry mix) } \\
\hline Quetiapine Fumarate & & 230.000 \\
\hline Cellulose, Microcrystalline & & 12.000 \\
\hline $\begin{array}{l}\text { Propylene Glycol Alginate } \\
\text { (Kelcoloid® K3B426) }\end{array}$ & Numeric & Factor $X_{1}$ \\
\hline Eudragit@ RS PO & Numeric & Factor $X_{2}$ \\
\hline \multicolumn{3}{|l|}{ Stage-B (Granulation) } \\
\hline Copovidone (Plasdone $® S-630)$ & & 12.000 \\
\hline Isopropyl alcohol & & Q.s. \\
\hline \multicolumn{3}{|l|}{ Stage-C (Lubrication) } \\
\hline Colloidal silicon dioxide & & 2.000 \\
\hline Magnesium stearate & & 5.000 \\
\hline \multicolumn{3}{|l|}{ Stage-D (Coating) } \\
\hline Opadry II Yellow 85F32004 & Categoric & Factor $X_{3}(24.000)$ \\
\hline ReadiLycoat & Categoric & Factor $X_{3}(24.000)$ \\
\hline Water, Purified* & & Q.s. \\
\hline
\end{tabular}

*Processing solvents, not present in the finished product ule, Mumbai, Inida). The individual tablets were placed in dissolution vessels containing $900 \mathrm{~mL}$ of $0.1 \mathrm{~N}$ hydrochloric acid or hydrochloric acid containing $40 \% \mathrm{v} / \mathrm{v}$ of alcohol. The study was conducted at a rotational speed of $200 \mathrm{rpm}$ for $120 \mathrm{~min}$. The sampling was done with an interval of $15 \mathrm{~min}$ as described by FDA guidance for quetiapine extended release tablets (6). The drug release from the formulations at $120 \mathrm{~min}$ was selected as responses. The in vitro drug release was also performed for Seroquel XL $200 \mathrm{mg}$ tablets in $0.1 \mathrm{~N}$ hydrochloric acid with and without $40 \% \mathrm{v} / \mathrm{v}$ ethanol.

\section{High-Performance Liquid Chromatography (HPLC) Analysis of Quetiapine}

The analysis of samples was performed using highperformance liquid chromatography (HPLC; Waters, 2695 separation module, Singapore) system equipped with quaternary pump, UV-Visible spectrophotometric detector (Perkin Elmer, Lambda 25, Massachusetts, USA), and C18 column (X-Terra; $150 \times 4.6 \mathrm{~mm}, 5 \mu \mathrm{m}$ ) at ambient temperature. The mobile phase used was a mixture of ammonium acetate buffer and acetonitrile at a ratio of 400:600. A flow rate of $1 \mathrm{~mL} / \mathrm{min}$ was maintained, and the detection wavelength was $292 \mathrm{~nm}$ (23). Required precision and accuracy of the HPLC method were checked and were found to be within limits (percent coefficient of variation was less than $15 \%$ ). Sample was filtered through $0.4 \mu$ membrane filter, diluted with mobile phase, and $10 \mu \mathrm{L}$ was spiked into column. 


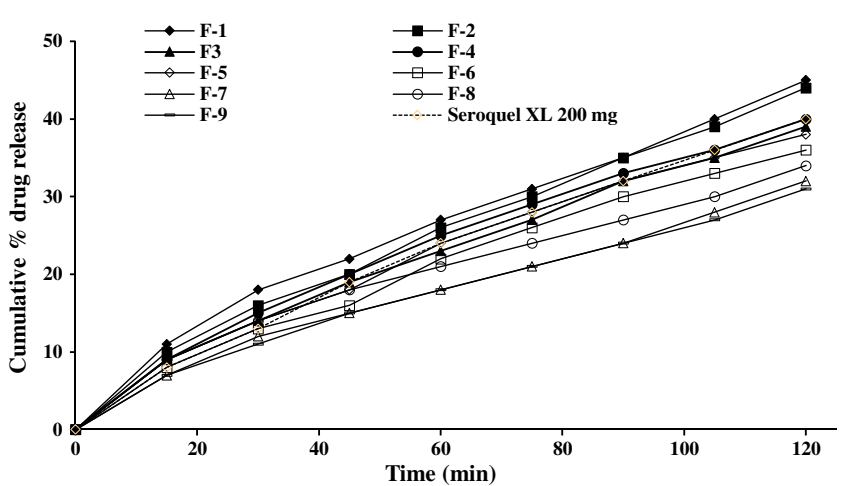

Fig. 1. In vitro release profiles of quetiapine prolonged release tablets $200 \mathrm{mg}$ in $0.1 \mathrm{~N}$ HCL (F1-F9 and Seroquel XL $200 \mathrm{mg}$ )

\section{Statistical Analysis}

Statistical comparisons were made using Student's $t$ test using statistical software tool (GraphPad Software, Inc., CA, USA). The results were considered significant at $95 \%$ confidence interval $(p<0.05)$ and were expressed as mean \pm SD.

\section{RESULTS}

\section{In Vitro Drug Release Studies}

The dissolution profiles of QF prolonged release tablets prepared using PGA and ERS are showed in Table I and Figs 1, 2, 3, and 4. Formulations F11 and F13 showed highest and lowest drug release at $120 \mathrm{~min}$, respectively, in $0.1 \mathrm{~N}$ hydrochloric acid. Whereas, 30 to $100 \%$ of the drug release was found (F13 and F11) in $0.1 \mathrm{~N}$ hydrochloric acid containing $40 \% v / v$ ethanol. Compositions F10, F11, and F17 had drug release of more than $80 \%$ in alcohol containing dissolution media.

\section{Design of Experiments}

A three-factor I-Optimal design was used to optimize the formulation variables. The independent variables and responses of all the experiments are shown in Table I. The effect of variables on responses (R1 and R2) is shown in Fig. 6.

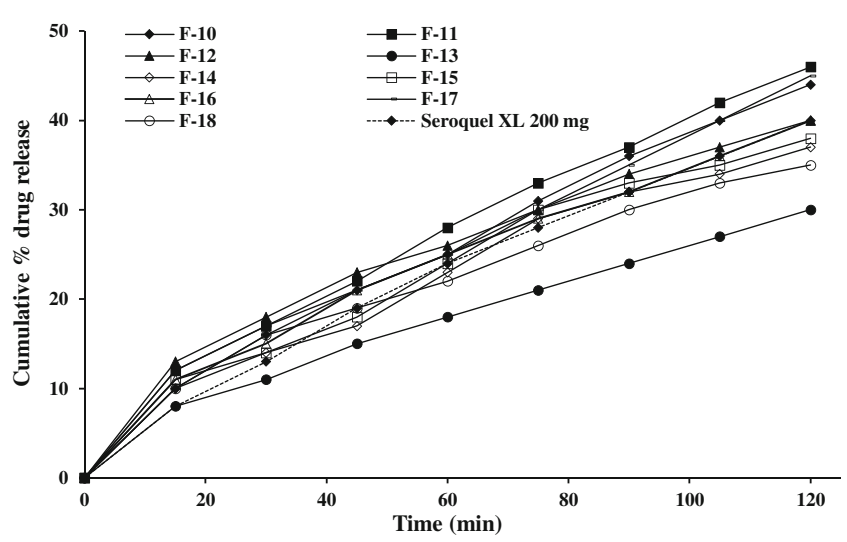

Fig. 2. In vitro release profiles of quetiapine prolonged release tablets $200 \mathrm{mg}$ in $0.1 \mathrm{~N}$ HCL (F10-F18 and Seroquel XL $200 \mathrm{mg}$ )

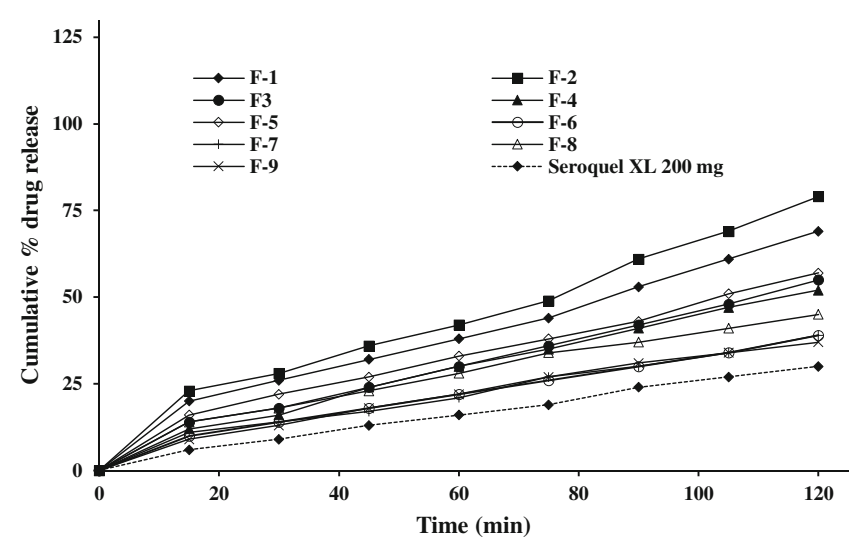

Fig. 3. In vitro release profiles of quetiapine prolonged release tablets $200 \mathrm{mg}$ in $0.1 \mathrm{~N} \mathrm{HCL}$ with $40 \% v / v$ ethanol (F1-F9 and Seroquel XL $200 \mathrm{mg}$ )

\section{Fitting Data to the Model}

The mathematical model was built using the analysis section of the software. The minimum and maximum responses for the response R1 were found to be 30 and $46 \%$, respectively. The data standalone was used for the development of the model. Mathematical transformation was required if the ratio of maximum to minimum was greater than 3 . Therefore, no mathematical transformation was performed for response R1 with ratios of 1.53 . The minimum and maximum values for the response $\mathrm{R} 2$ were found to be 30 and $100 \%$, respectively, with a ratio of 3.33 . Since the ratio was more than 3 , the data were transformed to other equation (inverse equation) in order to fit the mathematical model. The parameters of ANOVA are shown in Table III.

The response surface models (for R1 and R2) were calculated to estimate the quantitative effects for the different combination of factors and their levels using Design Expert. The models are shown in equation $\mathrm{A}$ and $\mathrm{B}$.

A. R1 (dissolution in $0.1 \mathrm{~N} \mathrm{HCl})=38.15-5.12 X_{1}-3.22$ $X_{2}+0.40 X_{3}$.

B. R2 (1/dissolution in $0.1 \mathrm{~N} \mathrm{HCl}$ containing $40 \%$ ethanol $)=0.019+0.00046 \quad X_{1}+0.00067 \quad X_{2}+0.001049$ $X_{3}+0.00018 X_{1}, X_{2}+0.000012 X_{1}, X_{3}+0.000051 X_{2}, X_{3}$.

The equations are useful for identifying the relative impact of the factors by comparing the factor coefficients.

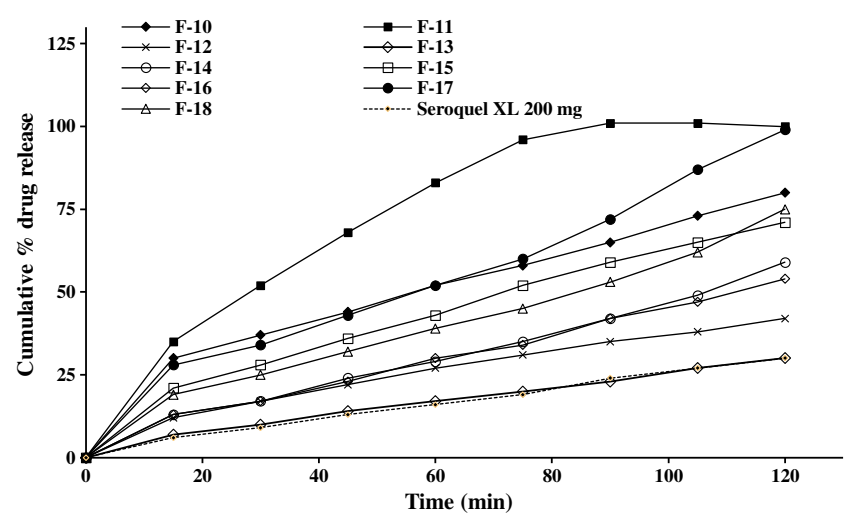

Fig. 4. In vitro release profiles of quetiapine prolonged release tablets $200 \mathrm{mg}$ in $0.1 \mathrm{~N} \mathrm{HCL}$ with $40 \% v / v$ ethanol (F10-F18 and Seroquel XL $200 \mathrm{mg}$ ) 
Table III. Summary of Results of Regression Analysis for Responses $\mathrm{R} 1$ and $\mathrm{R} 2$

\begin{tabular}{lll}
\hline Parameter & R1 & R2 \\
\hline Std. Dev. & 1.60 & $1.62 \times 10^{-3}$ \\
Mean & 38.56 & 0.019 \\
C.V. \% & 4.14 & 6.24 \\
PRESS & 57.29 & $4.64 \times 10^{-5}$ \\
R-Squared & 0.9151 & 0.9792 \\
Adj R-Squared & 0.8970 & 0.9679 \\
Pred R-Squared & 0.8637 & 0.9351 \\
Adeq Precision & 22.165 & 33.112 \\
\hline
\end{tabular}

\section{DISCUSSION}

\section{Discussion on In Vitro Drug Release Studies}

The oral controlled release formulations are designed in general based on dissolution, diffusion, or a combination of both the mechanisms. The prolonged release dosage forms are designed such a way that they release the drug over a long period of time usually longer than the typical dosing interval for a conventional formulation (24). Consumption of alcohol during the medication of prolonged release tablets may pose a serious risk to the safety of the patient because of the probability of dose dumping in the presence of alcohol. Regulatory agencies are thus stressing the sponsors to demonstrate that
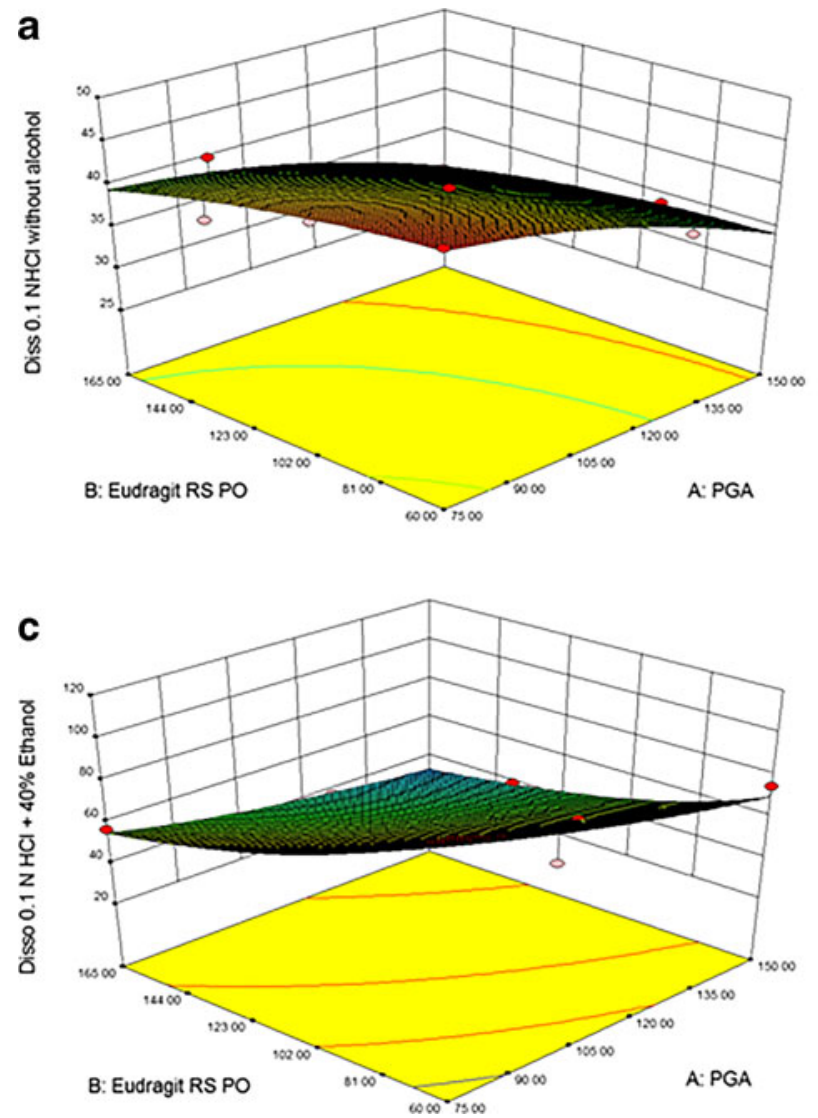

Fig. 5. 3-dimensional response surface plots. Response 1 is shown in a (Opadry II as $X_{3}$ ) and $\mathbf{b}$ (ReadiLycoat as $X_{3}$ ), response 2 is shown in $\mathbf{c}$ (Opadry II as X3) and $\mathbf{d}$ (ReadiLycoat as X3)

the prolonged release product applied for obtaining marketing authorizations is resistant to such type of alcohol-induced dose dumping (4).

The dissolution of Seroquel XL $200 \mathrm{mg}$ was about 40 and $30 \%$ in $0.1 \mathrm{~N} \mathrm{HCl}$ and $0.1 \mathrm{~N} \mathrm{HCl}$ containing $40 \% \mathrm{v} / \mathrm{v}$ ethanol, respectively, at $120 \mathrm{~min}$. To match the similarity norm, the novel formulation should also show similar dissolution in $0.1 \mathrm{~N}$ $\mathrm{HCl}$ and in $0.1 \mathrm{~N} \mathrm{HCl}$ containing $40 \% v / v$ ethanol. Hence, the limit of dissolution (target dissolution) was thus specified as $30-40 \%$ (4). The in vitro release studies were performed in $0.1 \mathrm{~N} \mathrm{HCl}$ containing no and highest proportion (40\%) alcohol. If the formulations show resistance to dose dumping in $40 \%$ alcoholic solution, then the same formulations are also anticipated to show resistance in low proportion alcoholic solutions. Therefore, the in vitro release studies were performed only in $0.1 \mathrm{~N} \mathrm{HCl}$ containing $40 \%$ alcoholic solutions apart from $0.1 \mathrm{~N} \mathrm{HCl}$. Among the experiments, four formulations with different proportions of PGA and ERS showed desired dissolution for response R1. Formulations F6, F7, F9, and F13 were the formulations that were meeting the target criteria demonstrating the satisfactory resistance to the alcohol-induced dose dumping. Compositions F6, F7, and F9 had a slightly more drug release in dissolution medium with alcohol compared to the drug release in medium without alcohol, at 120 min time point. Whereas, composition F13 has the same percentage of drug release in both the dissolution medium at $120 \mathrm{~min}$ time point. Therefore, composition F13 was a superior formulation than other three formulations in resisting alcohol-induced dose dumping. The results attrib-
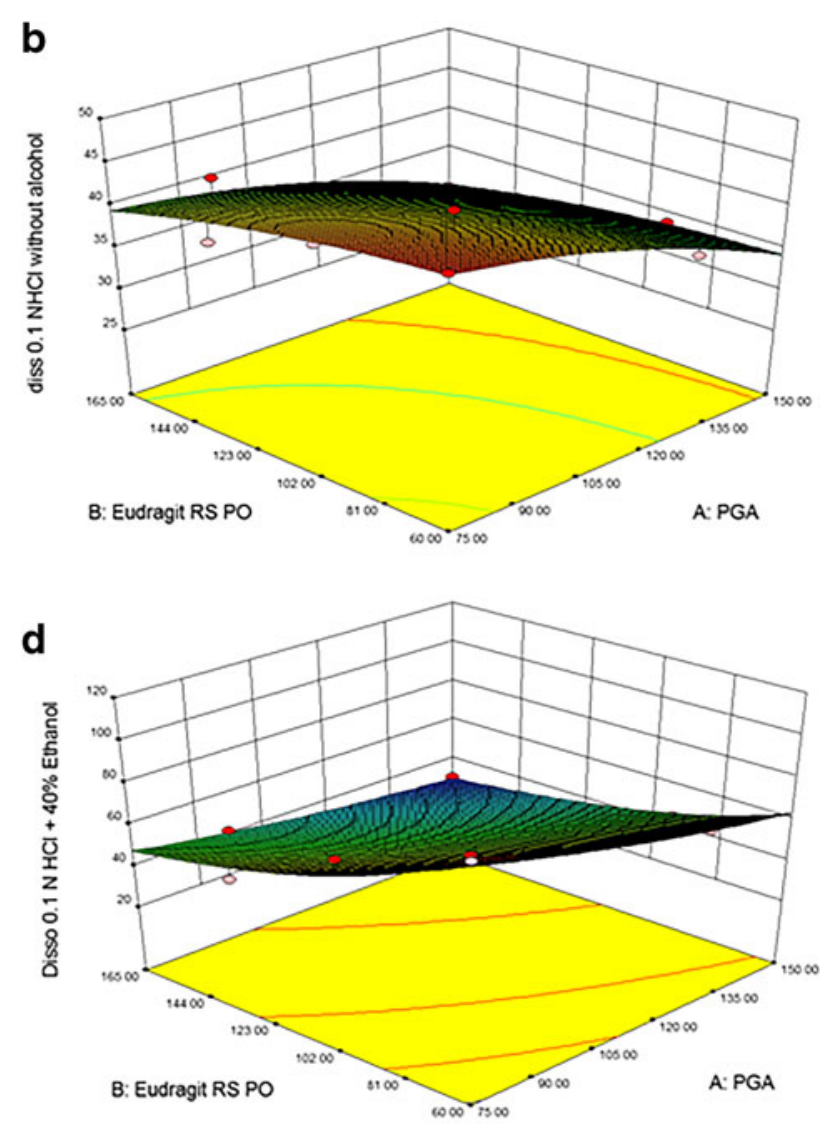

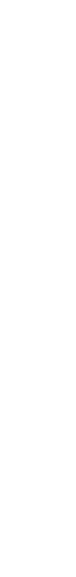


a

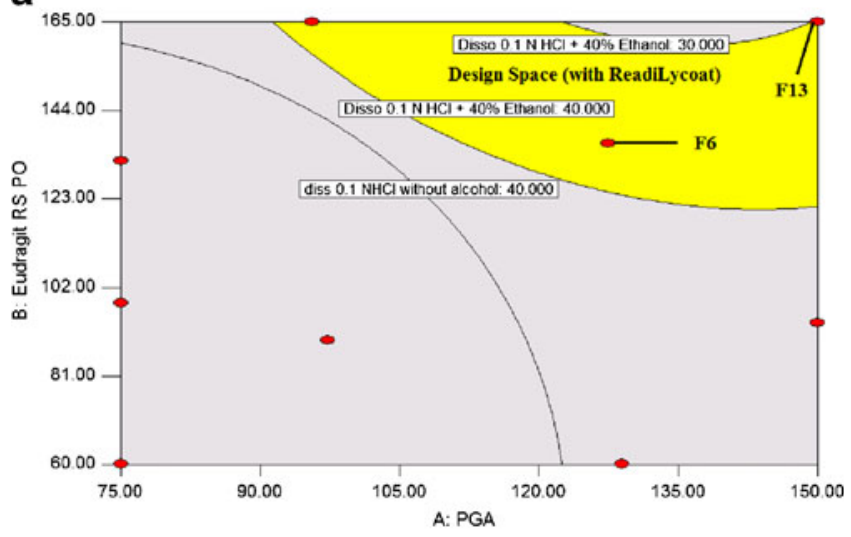

b

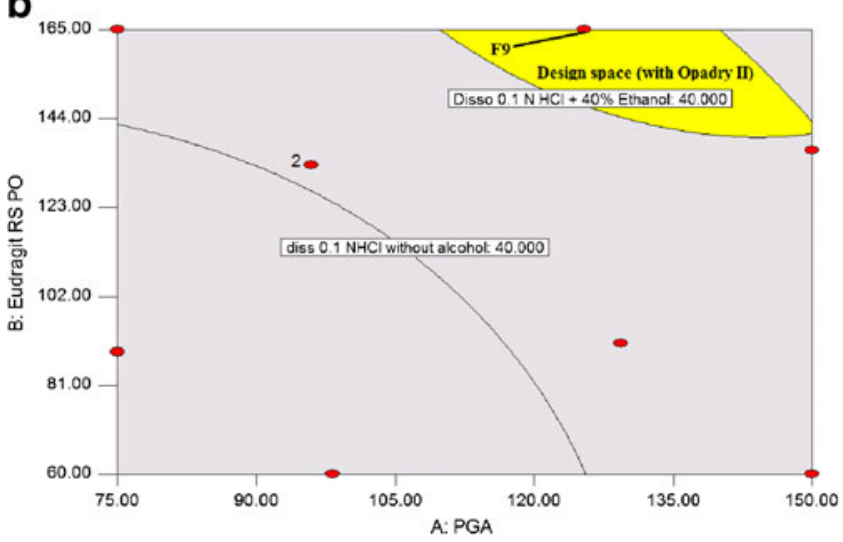

Fig. 6. Overlay plots to show the design space. a Design space plot for ReadiLycoat $\left(X_{3}\right)$. b Design space plot for Opadry $\operatorname{II}\left(X_{3}\right)$

uted that the composition of the formulation in terms of polymers and coating was strongly influencing the in vitro release. The drug release of 30 to $40 \%$ was to be achieved in alcohol containing media for the same composition to demonstrate resistance to alcohol-induced dose dumping. Thus, for a given composition, the drug release profile should be same in both the dissolution tests. The differences in the dissolution were due to the diverse properties of polymers. PGA is a water soluble polymer which swells immediately and forms gel-like structure when it comes in contact with water. Because of swelling property, PGA gives effective mucoadhesion and controlled release in aqueous dissolution mediums (5). In the pervasion of ethanol in $0.1 \mathrm{~N}$ hydrochloric acid, the gel gets eroded immediately (15). Addition of ERS with PGA in the tablet matrix was acting synergistically to resist an alcoholinduced dose dumping. It was assumed that ERS was providing structural support to the swollen and gelled mass of PGA and was reducing the erosion of PGA in alcohol containing dissolution media. ReadiLycoat consists of hydroxypropyl starch as a film former. It has poor solubility in alcohol. Therefore, ReadiLycoat was helping the tablets in resisting the alcohol when compared to Opadry II.

\section{Design Analysis}

The summary of ANOVA (Table III) suggests that the parameters for both the responses are meeting. The correlation coefficients are more than 0.91 for both the responses indicating the linearity of the respective models. The difference between the "predicted R-squared" and "adjusted Rsquared" was below 0.2. The "Adeq Precision" (signal to noise ratio) of the responses R1 and R2 were found to be 22.165 and 33.112 , respectively. The results indicated that the mathematical equations generated were sufficient for the optimization of composition and navigation of design space.

\section{Three-Dimensional Plots and Response Surface Analysis}

Three-dimensional response surface plots are shown in Fig. 5a-d, which are very useful to study the interaction effects of the factors on the responses. The plots are useful in studying effects of two factors on the response at one time. In all the depicted figures, the third variable was kept at a constant level. In other words, the effect of change in PGA and ERS concentrations on in vitro release profiles in $0.1 \mathrm{~N}$ hydrochloric acid with and without alcohol is presented. The plots show that the dissolution was decreasing linearly in $0.1 \mathrm{~N}$ hydrochloric acid with increase in PGA concentration from 75 to $150 \mathrm{mg}$. The increase in concentration of ERS from 60 to $165 \mathrm{mg}$ has further decreased the quetiapine dissolution. There was no significant difference $(p<0.05)$ in dissolution rate and extent for tablets with coating materials Opadry II and ReadiLycoat in dissolution media $0.1 \mathrm{~N}$ hydrochloric acid. Curvilinear decrease was observed for R2 with increase in levels of PGA and ERS. At the highest concentration of these two polymers in the tablets, the dissolution in alcohol containing media was least. Drug release from formulations coated with ReadiLycoat (Fig. 6a) was less compared with formulation coated with Opadry II (Fig. 6b) in alcohol containing

Table IV. Validation of the Design Model

\begin{tabular}{|c|c|c|c|c|c|c|c|c|}
\hline \multirow[t]{3}{*}{ Experiment } & \multirow{2}{*}{\multicolumn{2}{|c|}{$\frac{\text { Variables }}{X_{1} ; X_{2} ; X_{3}}$}} & \multicolumn{4}{|c|}{ Responses } & \multicolumn{2}{|l|}{ PE } \\
\hline & & & \multirow{2}{*}{$\begin{array}{l}\text { R1 } \\
\text { Predict }\end{array}$} & \multirow[t]{2}{*}{$\mathrm{R} 2$} & \multirow{2}{*}{\multicolumn{2}{|c|}{ Experimental }} & \multirow[t]{2}{*}{$\mathrm{R} 1$} & \multirow[t]{2}{*}{$\mathrm{R} 2$} \\
\hline & Predicted & Experimental & & & & & & \\
\hline 1 & 150.0; 165.0; ReadiLycoat & 150.0; 165.0; ReadiLycoat & 30.3 & 30.0 & 30 & 30 & -1.0 & 0.0 \\
\hline 2 & 75.0; 98.3; ReadiLycoat & 75.0; 98.3; ReadiLycoat & 44.3 & 76.8 & 44 & 80 & -0.7 & 4.0 \\
\hline 3 & 97.2; 89.4; ReadiLycoat & 97.2; 89.4; ReadiLycoat & 42.9 & 66.4 & 45 & 69 & 4.7 & 3.8 \\
\hline 4 & $150.0 ; 60.0 ;$ Opadry II & $150.0 ; 60.0 ;$ Opadry II & 34.8 & 70.3 & 35 & 75 & 0.6 & 6.3 \\
\hline 5 & $75.0 ; 165.0 ;$ Opadry II & $75.0 ; 165.0 ;$ Opadry II & 37.4 & 58.1 & 38 & 57 & 1.6 & -1.9 \\
\hline 6 & $150.0 ; 136.5$; Opadry II & $150.0 ; 136.5$; Opadry II & 30.5 & 40.9 & 32 & 39 & 4.7 & -4.9 \\
\hline
\end{tabular}


dissolution media. It indicated that RediLycoat was showing more resistance for the dissolution in media containing alcohol compared to Opadry II.

\section{Validation of the Model}

Six checkpoint compositions were gathered from the RSM, the formulation and predicted responses are shown in Table IV. The predicted and experimental responses are compared in order to validate the model and to calculate the prediction error. The prediction error was found to be below $7 \%$ indicating that the observed responses were very close to the predicted values. Percentage prediction error is useful in constituting the validity of generated equations and describes how close the predicted responses to that of actual values. The values of $<15$ are desirable to have closeness of the predicted values with the actual values (25).

\section{Optimization and Design Space}

The constraints are set to find out the range of composition that met the target dissolution. The targets of both the responses are fixed as $30-40 \%$ at $120 \mathrm{~min}$ based on Seroquel® XL $200 \mathrm{mg}$ dissolution profiles (Figs. 1, 2, 3 , and 4). In the same section criteria, the independent variables were set at their minimum and maximum ranges. Composition F13 was the best composition from the trials that was meeting the desired dissolution profiles in both the dissolution media and was the only composition that had same drug release in media with and without alcohol. Benefit of design of experiments was that with the available responses for the controlled variables, it was possible to have more than one formulation which may meet the targeted dissolution. Overlay plots for responses R1 and R2 generated design space (Fig. 6). Design space for compositions coated with Opadry II was very narrow compared to the formulations coated with ReadiLycoat. Any combination of PGA and ERS from the design space can assure resistance to alcohol-induced dose dumping. As depicted in Fig. 6, to prepare a formulation of quetiapine prolonged release tablets resistant to alcohol-induced dose dumping, minimum polymer levels of PGA and ERS required are 95 and $120 \mathrm{mg}$ when $24 \mathrm{mg}$ of Readylycoat was coated. With $24 \mathrm{mg}$ of Opadry II coating on the tablets, minimum polymer levels required for the same purpose are $110 \mathrm{mg}$ of PGA and $140 \mathrm{mg}$ of ERS.

\section{CONCLUSIONS}

PGA alone in the tablet matrix cannot resist alcoholinduced dose dumping. The current study conclusively demonstrates the use of I-Optimal statistical design was valid for predicting the optimum quetiapine prolonged release tablets $200 \mathrm{mg}$ formulation which resists to alcohol-induced dose dumping. The derived polynomial equations, threedimensional response surface diagrams and overlay plots aid in predicting the values of the selected independent variables which can give desired dissolution profiles $0.1 \mathrm{~N}$ hydrochloric acid. Quetiapine prolonged release tablets prepared using a novel combination of polymers PGA and ERS at levels above 95 and $120 \mathrm{mg}$, respectively, and coated with ReadiLycoat, as per the derived design space can resist to alcohol-induced dose dumping.

\section{ACKNOWLEDGMENTS}

Authors acknowledge the contribution received from $\mathrm{Mr}$. Veluswamy Balasubramanian and Mr. Vikram Reddy

Conflict of interest The authors declare that they have no competing interests.

\section{REFERENCES}

1. Maryadele JO. The Merck index. 13th ed. New Jersey: Merck \& CO., Inc.; 2001.

2. Physicians' desk reference. 64th ed. Seroquel XR. New Jersey: PDR Network; 2010. 759 p.

3. Anand O, Yu LX, Conner DP, Davit BM. Dissolution testing for generic drugs: an FDA perspective. AAPS J. 2011;13(3):328-35. doi:10.1208/s12248-011-9272-y.

4. Robert JM, Ajaz SH. FDA's ACPS Meeting. Awareness topic: Mitigating the risks of ethanol induced dose dumping from oral sustained/controlled release dosage forms. 2005. http:// www.fda.gov/ohrms/dockets/ac/05/briefing/2005-4187B1_01_08Alcohol-Induced.pdf. Accessed 28 August 2013.

5. Gujjar CY, Rallabandi BRC, Deulkar VS. Mucoadhesive formulation of Quetiapine fumarate prepared using non-gelling polymer and effective thickening agent. Nov Sci Int J Pharm Sci. 2013;2(3-4):88-92.

6. FDA's Draft guidance on Quetiapine Fumarate. Recommended Jun 2008, revised Jul 2009. http://www.fda.gov/downloads/Drugs/.../ Guidances/UCM089520.pdf. Accessed 08 November 2011.

7. Jedinger N, Khinast J, Roblegg E. The design of controlledrelease formulations resistant to alcohol-induced dose dumpinga review. Eur J Pharm Biopharm. 2014;87(2):217-26. doi:10.1016/ j.ejpb.2014.02.008.

8. Johnson F, Wagner G, Sun S, Stauffer J. Effect of concomitant ingestion of alcohol on the in vivo pharmacokinetics of KADIAN (morphine sulfate extended-release) capsules. J Pain. 2008;9(4):330-6. doi:10.1016/j.jpain.2007.11.009.

9. Public Health Advisory: Suspended marketing of Palladone (hydromorphone hydrochloride, extended-release capsules). 1307-2005. http://www.fda.gov/Drugs/DrugSafety/ PostmarketDrugSafetyInformationforPatientsandProviders/ DrugSafetyInformationforHeathcareProfessionals/ PublicHealthAdvisories/ucm051743.htm. Accessed 25 August 2013.

10. Rosiaux Y, Muschert S, Chokshi R, Leclercq B, Siepmann F, Siepmann J. Ethanol-resistant polymeric film coatings for controlled drug delivery. J Control Release. 2013;169(1-2):1-9. doi:10.1016/j.jconrel.2013.04.001.

11. Shahrzad M, Kurt AF, Ali RR. Investigation of the effects of hydroalcoholic solutions on textural and rheological properties of various controlled release grades of hypromellose. AAPS PharmSciTech. 2009;10(1):77-80. doi:10.1208/s12249-008-9181-2.

12. Mohuri G, inventor, Alpharma Inc., assignee. Alcohol resistant pharmaceutical formulations. United States patent application publication. US2009/0155337 A1. 2009 Jun 18

13. Effect of alcohol on the drug dissolution properties of tablets formulated with Carbopol polymers. Technical data sheet Lubrizol. TDS-793, 2011 Nov 7. http://www.lubrizol.com/Life-Science/Documents/Pharmaceutical/Technical-Data-Sheets/TDS793-Effect-of-Alcohol-on-the-Drug-Dissolution-Properties-ofTablets-Formulated-with-Carbopol-Polymers.pdf. Accessed 28 August 2013.

14. Roy SB, Kulkarni SK, Panchal MK, Shah KY, inventors, Pharmaceutical compositions for reducing alcohol-induced dose dumping. United States patent application publication. US20120207825 A1.2012 Aug 16. 
15. Nause RG, Reddy RD, Soh LJP. Propylene Glycol Alginate. In: Raymond CR, Paul JS, Marian EQ, editors. Handbook of pharmaceutical excipients. 6th ed. London: Pharmaceutical Press; 2009. p. 594-5.

16. Chang RK, Peng Y, Trivedi N, Shukla AJ. Polymethacrylates. In: Raymond CR, Paul JS, Marian EQ, editors. Handbook of pharmaceutical excipients. 6th ed. London: Pharmaceutical Press; 2009. p. 525-33.

17. Opadry ${ }^{\circledR}$ II High performance film coating systems. Product information sheet [Internet]. 2009. http://www.colorcon.com/litera t u re / m a rke t i n g/f c/O p a d r y \% 20 I I / pi_opadry_II_coat_param_clear.pdf. Accessed 28 August 2013.

18. Abubakar O. Polyvinyl Alcohol. In: Raymond CR, Paul JS, Marian EQ, editors. Handbook of pharmaceutical excipients. 6th ed. London: Pharmaceutical Press; 2009. p. 564-5.

19. Shah SA, Thassu D. Hydroxypropyl Starch. In: Raymond CR, Paul JS, Marian EQ, editors. Handbook of pharmaceutical excipients. 6th ed. London: Pharmaceutical Press; 2009. p. 325-6.

20. Computer-generated optimal designs. In: Mark JA, Patrick JW, editors. RSM Simplified optimizing processes using response surface methods for design of experiments. Boca Raton: CRC press; 2005. p. 149-165.

21. Piepel GF. Programs for generating extreme vertices and centroids of linearly constrained experimental regions. J Quality Technol. 1988;20(2):125-39.

22. Rutchatz D, Gujjar CY, Rallabandi RCB, Pasahn ML, inventors, Alfred E. Tiefenbacher, applicant. Quetiapine prolonged-release tablets. World intellectual property organization. WO2011/ 154118 A1. 2011 Dec 15

23. Pramod LI, Sampada DD, Sachin VG, Laxmileena DP, Deepali DJ, Yogita AK. Development of analytical method for determination of quetiapine fumarate in bulk \& tablet dosage form. Pharma Chem. 2013;5(5):26-30.

24. Controlled release medication. In: Brahmankar DM, Sunil BJ, editors. Biopharmaceutics and pharmacokinetics a treatise. Delhi: Vallabh prakashan; 1999. p. 335-375.

25. Gannu R, Yamsani VV, Yamsani SK, Palem CR, Yamsani MR. Optimization of hydrogels for transdermal delivery of lisinopril by Box-Behnken statistical design. AAPS PharmSciTech. 2009;10(2):505-14. doi:10.1208/s12249-009-9230-5. 